3 Dogra S, Falconer R, Latto IP. Successful difficult intubation. Tracheal tube placement over a gum-elastic bougie. Anaesthesia 1990; 45: 774-6.

4 Carr R, Reyford H, Belani K, Boufflers E, KrivosicHorber R, Palabniuk R. Evaluation of the Augustine guide $^{\mathrm{TM}}$ for difficult tracheal intubation. Can J Anaesth 1995; 42: 1171-5.

5 The difficult intubation. In: Ovassapian A (Ed). Fiberoptic Airway Endoscopy in Anesthesia and Critical Care. New York: Raven Press, 1990: 135-48.

\section{Special challenges with new digital anesthesia machines}

To the Editor:

Dr. Doyle is absolutely correct in observing the challenges of the new computerized anesthesia workstations, ${ }^{1}$ which I am certain do not apply only to systems from Datex-Ohmeda. We have similar, though different, observations, complaints, and cautions in regards to our anesthesia delivery units (ADU).

I would offer an extension to his comments on software 'upgrades' and the recommendation to "ask for free software upgrades for the life of the product", inasmuch as our medical supply companies have learned lessons from the major software companies and are trying to make a somewhat artificial distinction between 'updates' and 'upgrades'. They claim that 'updates' fix 'bugs' and 'upgrades' extend functionality, and 'upgrades' are therefore worth the $\$ 2000$ they charge. I am personally unable to see the clinical importance of that distinction when software 'changes', even those changes which add new features, address issues which I have with the functioning of the machine.

I suggest that buyers ensure that the contract language specifies that the provision of software 'developments' are included in the purchase price for the life of such computer-based medical equipment.

Canadian anesthesiologists should be reminded of the CAS Equipment Information Exchange Database at www.anesthesia.org/cas where specific equipment problems of the nature discussed can be reported and shared.

Richard N. Merchant MD FRCPC

New Westminster, British Columbia

\section{Reference}

1 Doyle DJ. New Media. Special challenges with new digital anesthesia machines. Can J Anesth 2001; 48: $609-10$.

\section{REPLY:}

Dr. Merchant makes some excellent points about the problems associated with software-based anesthesia machines. Although medical equipment manufacturers are slowly coping with the special challenges introduced when computers are embedded into medical products, it is apparent that not all manufacturers are committed to careful ergonomic evaluation of their products.

The ideal anesthesia machine design should be intuitive and error-tolerant ${ }^{1,2}$ and should also contribute to improved situational awareness. ${ }^{3}$ At the moment such systems are still largely lacking. However, this matter will almost certainly change now that organizations such as the Emergency Care Research Institute (ECRI) ${ }^{4}$ and individuals such as Dr. John Oyston ${ }^{5}$ are publicizing the problem of user hostile anesthesia machine designs.

D. John Doyle MD PhD FRCPC

Toronto, Ontario

\section{References}

1 Cook RI, Woods DD. Adapting to new technology in the operating room. Hum Factors 1996; 38: 593-613.

2 Gravenstein JS. How does human error affect safety in anesthesia? Surg Oncol Clin N Am 2000; 9: 81-95.

3 Gaba DM, Howard SK, Small SD. Situation awareness in anesthesiology. Hum Factors 1995; 37: 20-31.

4 ECRI. Anesthesia systems. Health Devices 1996; 25 : 158-211.

5 John Oyston. A Critical Review of the Siemens KION Anesthesia Workstation. http://www.oyston.com/kion/ 